\title{
Phenotype-genotype analysis in patients with GnRH deficiency in a single center
}

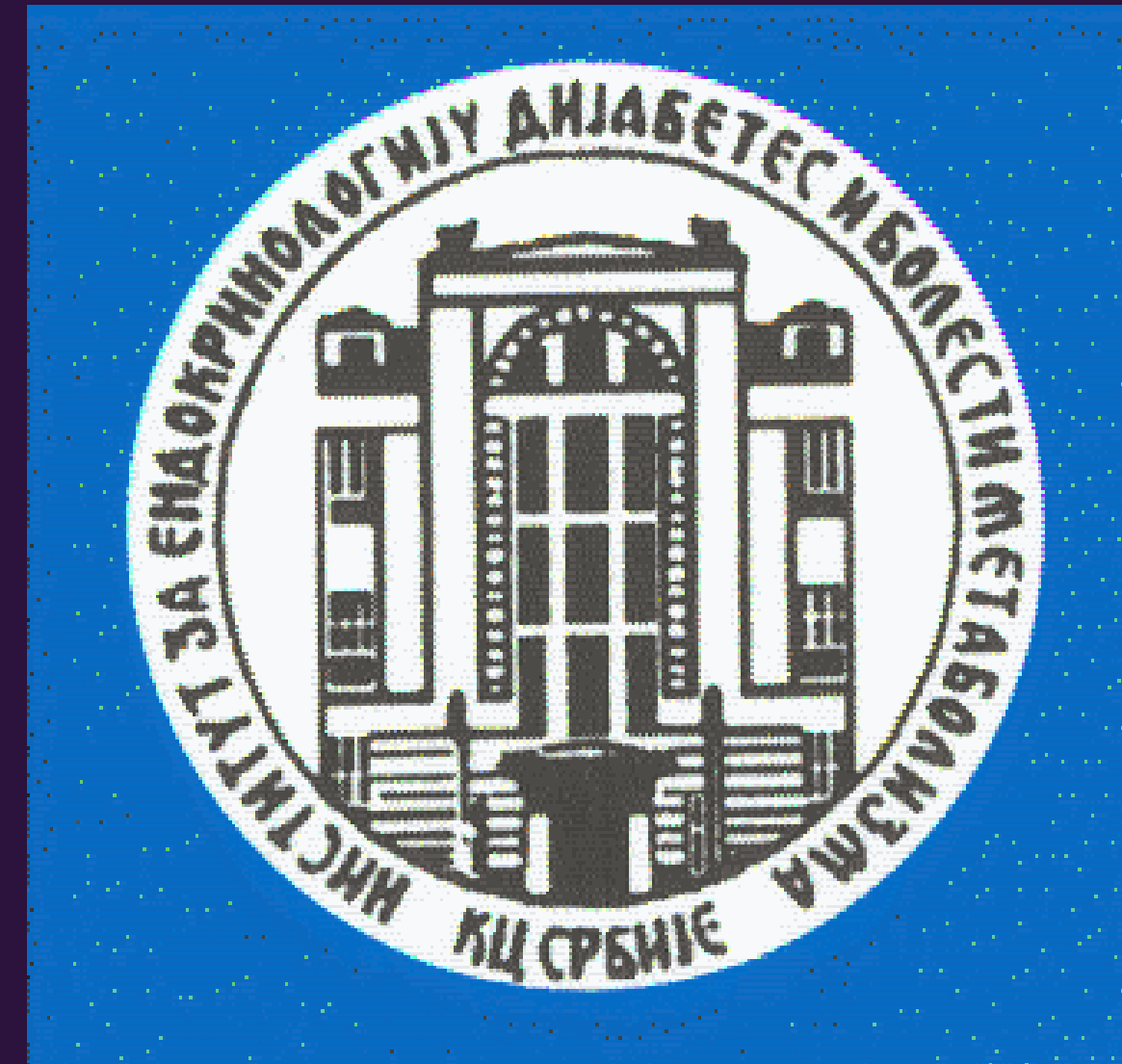

Pekic $\mathrm{S}^{1,2}, \mathrm{Xu} \mathrm{C}^{3}$, Dwyer $\mathrm{A}^{3}$, Cassatella $\mathrm{D}^{3}$, Doknic $\mathrm{M}^{1,2}$, Miljic $\mathrm{D}^{1,2}$, Stojanovic $\mathrm{M}^{1,2}$, Petakov $\mathrm{M}^{1,2}$, Pitteloud N3 , Popovic V2

${ }^{1}$ Department of Neuroendocrinology, Clinic for Endocrinology, Diabetes and Diseases of Metabolism, University Clinical Center, Belgrade, Serbia; ${ }^{2}$ School of Medicine, University of Belgrade; ${ }^{3}$ Endocrinology, Diabetes and Metabolism Service of the Centre Hospitalier Universitaire Vaudois (CHUV), du Bugnon 46, Lausanne 1011, Switzerland

CONCLUSION: This CHH cohort displays marked clinical heterogeneity including patients with 4H syndrome, CHARGE syndrome and congenital adrenal hypoplasia. We identified mutations in the majority $(80 \%)$ of cases and those patients without mutations did not exhibit any $\mathrm{CHH}-$ associated phenotypes. Exome sequencing is an efficient and effective tool for exploring the complex genetic architecture of $\mathrm{CHH}$.

BACKGROUND: Congenital hypogonadotropic hypogonadism $(\mathrm{CHH})$ results from isolated $\mathrm{GnRH}$ deficiency and may present with normal sense of smell $(\mathrm{nCHH})$, anosmia (Kallmann syndrome, KS) or in syndromic forms. Genetic defects are identified in approximately half of $\mathrm{CHH}$ cases and oligogenicity is noted in almost $10 \%$. Further, spontaneous reversal of is seen in $15 \%$ of patients.
DESIGN: We analyzed the clinical characteristics of 37 Serbian $\mathrm{CHH}$ probands (34 sporadic, 3 familial). Genetic testings are available in 15 patients (Pitteloud, Switzerland; Tuttelmann, Germany; Bernard, Canada). Prof Pitteloud group: Genetic analyses of probands were conducted using Sanger $(n=4)$ and exome sequencing $(n=11)$. Rare variants (minor allele frequency $<1 \%$ ) were considered mutations if they were nonsense, frameshift, splice-site-altering variants or missense variants predicted to be deleterious in silico.

RESULTS: We analyzed clinical characteristics of 37 Serbian CHH probands (34 sporadic, 3 familial; Table 1)

\begin{tabular}{|c|c|c|c|c|c|}
\hline & $\begin{array}{l}\text { Kallmann Sy } \\
n=11(30 \%)\end{array}$ & $\begin{array}{l}\text { Normosmic HH } \\
\qquad \mathrm{n}=22(59 \%)\end{array}$ & $\begin{array}{c}\mathrm{CHH}+\text { Congenital Adrenal } \\
\text { Hypoplasia } \\
\mathrm{n}=1\end{array}$ & $\begin{array}{c}\text { Sy CHARGE } \\
n=1\end{array}$ & $\begin{array}{c}\text { Leukodystrophy } \\
\begin{array}{c}4 \mathrm{H} \text { Sy } \\
\mathrm{N}=2\end{array}\end{array}$ \\
\hline $\begin{array}{l}\text { Age at diagnosis } \\
\text { (average, range ) }\end{array}$ & $\begin{array}{c}\mathbf{1 7 . 2} \\
16-22\end{array}$ & $\begin{array}{l}23.3 * \\
15-50\end{array}$ & 16 & 18 & 20 \\
\hline $\begin{array}{l}\text { Age at follow-up } \\
\text { (average, range) }\end{array}$ & $\begin{array}{c}\mathbf{2 6 . 5} \\
19-41\end{array}$ & $\begin{array}{c}33.9 \\
19-79\end{array}$ & 19 & & $\begin{array}{c}28 \\
20-32\end{array}$ \\
\hline Familial cases & $\begin{array}{c}1 \text { family: } 2 \\
\text { brothers }\end{array}$ & $\begin{array}{c}2 \text { families: } \\
\text { brother \& sister } \\
5 \text { brothers \& } \\
\text { sister }\end{array}$ & - & - & - \\
\hline Cryptorchidism & 4 & 4 & NROB1 mutation & - & POLR3A mutation \\
\hline Cleft palate & - & 1 & - & - & - \\
\hline
\end{tabular}

- Sy CHARGE: Coloboma / Heart defects / Atresia of choanae / Retarded growth / Genital anomalies / Ear defects -Sy 4H: Hypomyelination / Hypodontia / Hypogonadotropic Hypogonadism

Family1: two brothers with KS and a novel mutation in FGFR1 Family 2: brother and sister with $\mathrm{nHH}$. Brother has periodic hypokalemic paralysis and gene (heterozygote c-570G>A; Tuttelmann, Human Genetics, agenesis of septum pellucidum. Exome sequencing revealed oligogenicity in brother Munster, Germany). The older brother reversed (heterozygous mutations in FGFR1, GNRH1, and LEP) and he is the only patient with hypogonadotropic hypogonadism and at age 42 was diagnosed oligogenicity (1/11 tested patients). Genetic analysis in sister revealed heterozygous with a pituitary tumor-macroprolactinoma (MRI). Their father mutation in FGFR1.

had delayed puberty.

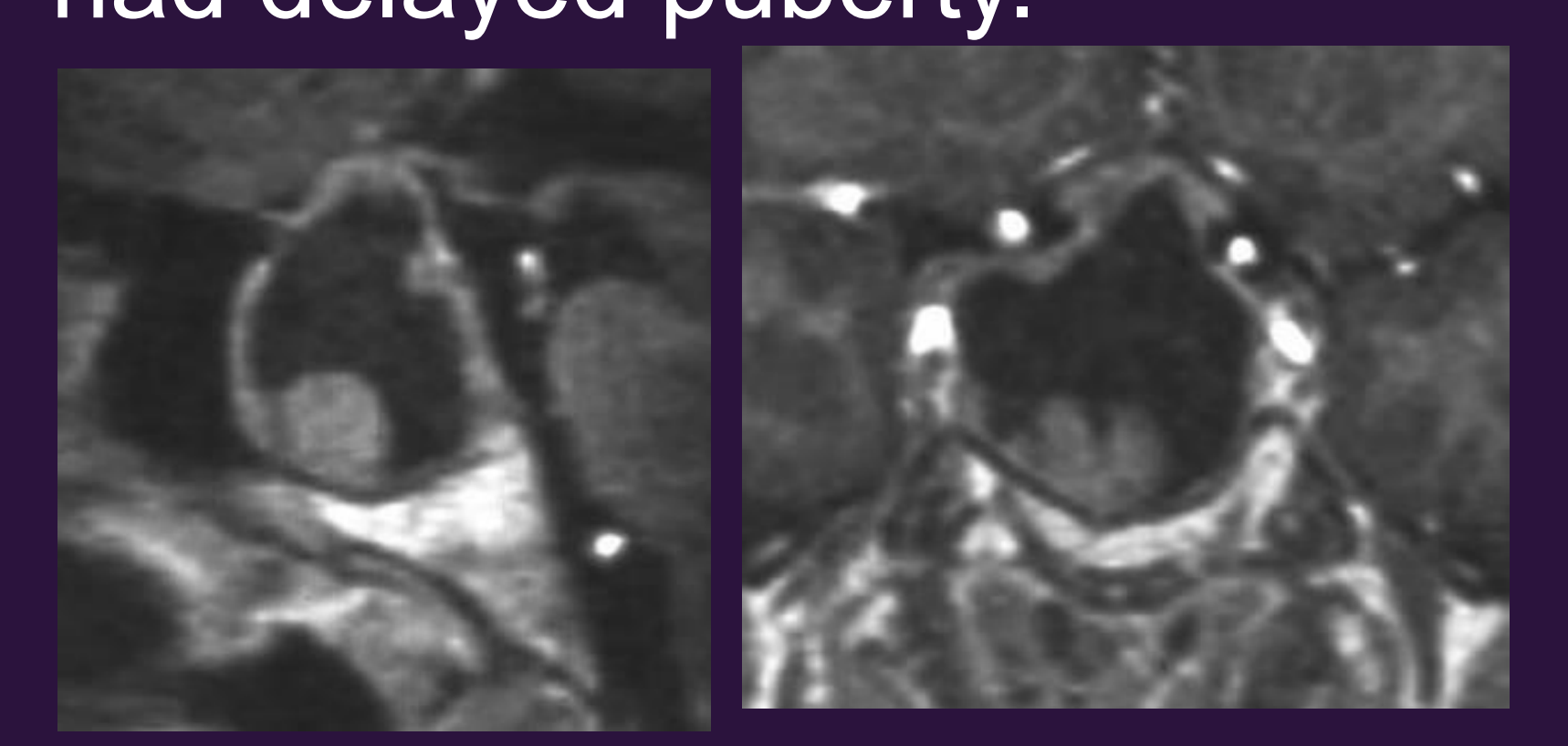

Family 3: a large family with 8 children (5 brothers and 1 sister with $\mathrm{nHH}$ and a novel mutation in FGFR1 gene (heterozygote c-1552+1G>A; Tuttelmann, Germany). Their mother was the carrier of the same mutation. Two members from this family had cleft palate.

Genetic studies revealed mutations in 11 different loci in $12 / 15(80 \%)$ unrelated probands

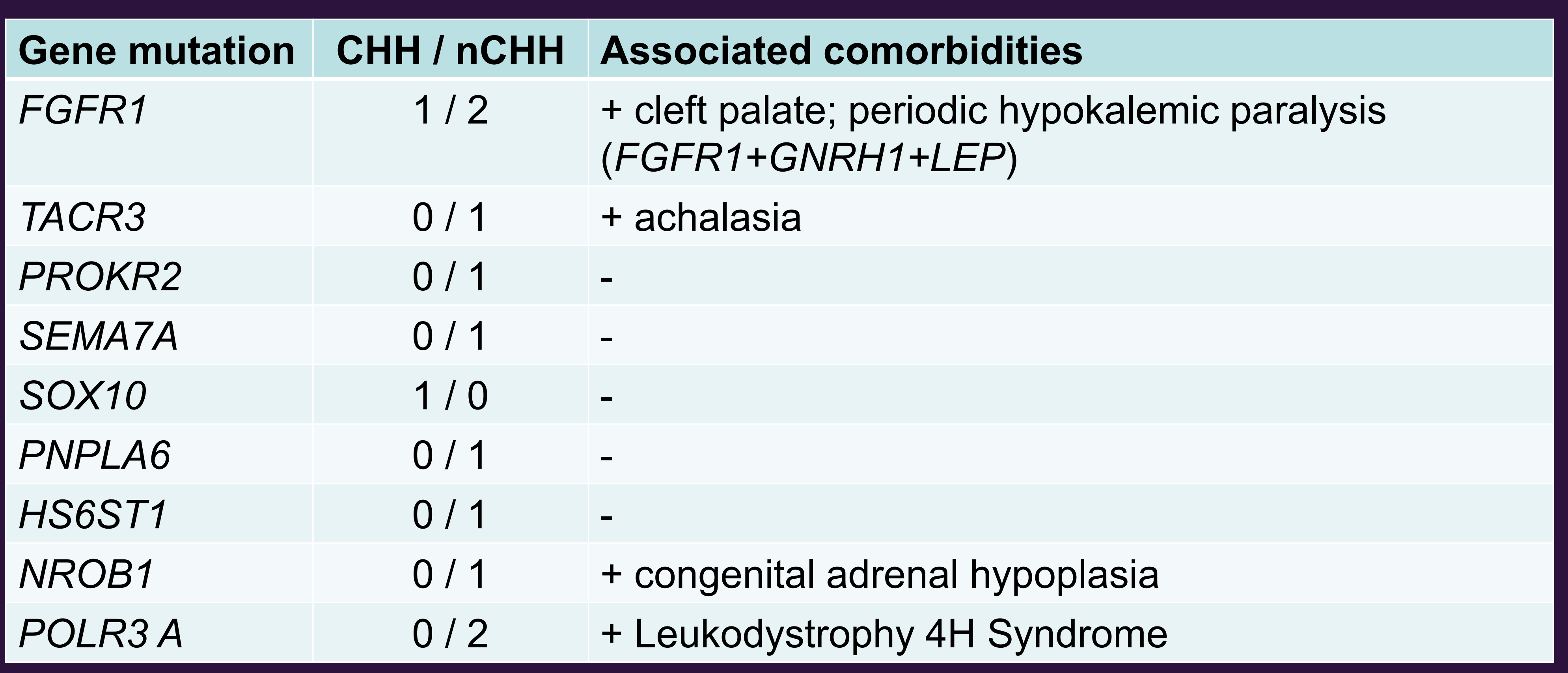

Leukodystrophy 4H Syndrome: Additional observations: hypoprolactinemia, thinned corpus callosum, small pituitary gland
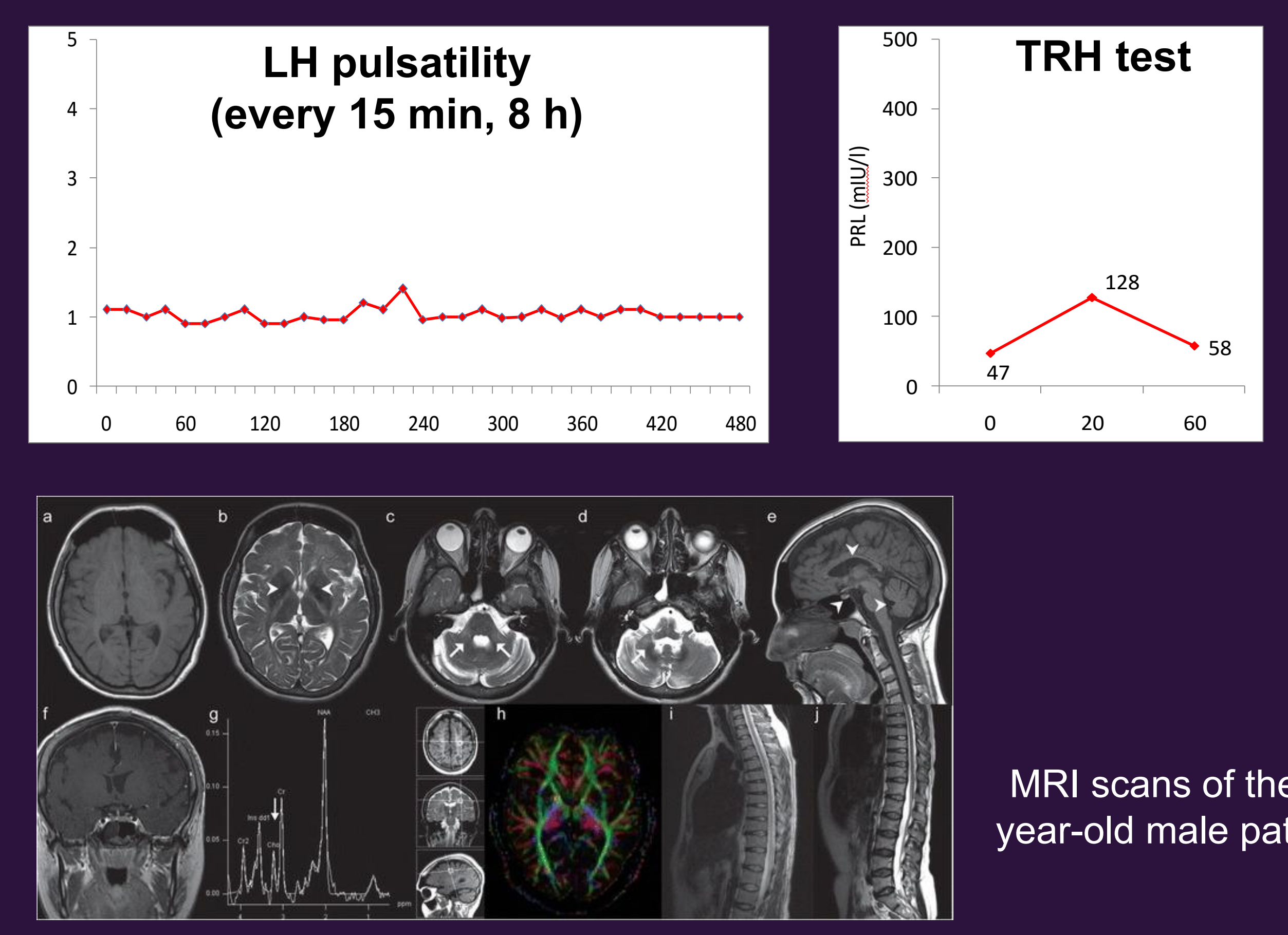

MRI scans of the brain of a 20 year-old male patient with $4 \mathrm{H}$ Sy

REVERSIBLE CHH: Three male reversal cases were noted among the 33 $\mathrm{KS} / \mathrm{nCHH}(10 \%)$. Two of three reversal cases were found to carry heterozygous mutations (FGFR1 and TACR3, respectively)

HYPOTHALAMIC-PITUITARY IMAGING (MRI): in 11 patients pituitary MRI scans were normal, while some abnormalities were described in others: pituitary microadenoma ( $\mathrm{n}=5$ ), pineal cyst $(n=1)$, agenesis of septum pellucidum $(n=1)$, agenesis of corpus callosum $(n=1)$, empty sella $(n=1)$, pituitary hypoplasia $(n=3)$, and macroprolactinoma $(n=1$, at age 42$)$ 